\title{
Entschädigung muss sein
}

Wettbewerbsverbot bei Angestellten. In seinem Urteil vom 22. März 2017 (10 AZR 448/15) beschäftigt sich das Bundesarbeitsgericht (BAG) mit der Frage, ob ein nachvertragliches Wettbewerbsverbot wirksam bleiben kann, auch wenn für den Arbeitnehmer keine Karenzentschädigung gezahlt wird. Diese Entscheidung ist auch für Zahnärzte von Relevanz, um nachvertragliche Wettbewerbsverbote korrekt zu gestalten.

AUTOR: RA MICHAEL LENNARTZ

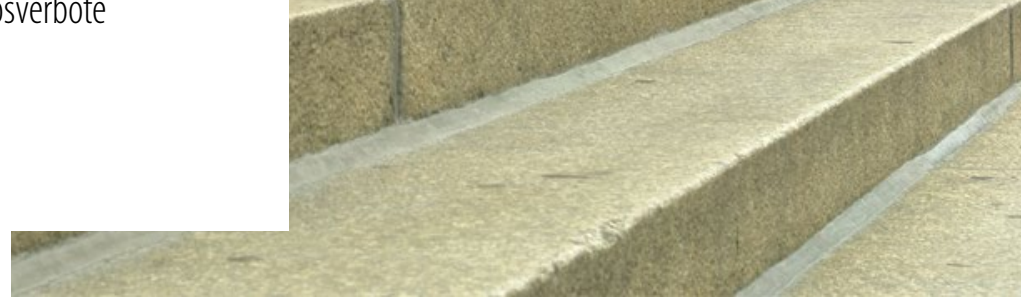

\section{DER FALL}

In dem konkreten Fall wurde in einem Arbeitsvertrag mit einer Industriekauffrau ein Wettbewerbsverbot vereinbart, welches der Arbeitnehmerin untersagte, für die Dauer von zwei Jahren nach Beendigung des Vertrags in selbstständiger, unselbstständiger oder sonstiger Weise für ein Unternehmen tätig zu sein, das mit dem Arbeitgeber in direktem oder indirektem Wettbewerb steht. Im Arbeitsvertrag war für jeden Fall der Zuwiderhandlung eine Vertragsstrafe von 10.000 Euro vorgesehen. Eine sogenannte Karenzentschädigung, also eine Entschädigung des Arbeitnehmers, wenn er sich an das Wettbewerbsverbot hält, sah der Arbeitsvertrag nicht vor.

Im Arbeitsvertrag gab es eine sogenannte „salvatorische Klausel“, wonach der Vertrag im Übrigen unberührt bleiben soll, wenn eine Bestimmung nichtig oder unwirksam ist. Anstelle der nichtigen oder unwirksamen Bestimmung sollte dabei eine angemessene Regelung gelten.

\section{DIE ENTSCHEIDUNG}

In seinem Urteil macht das BAG unmissverständlich klar, dass ein nach- vertragliches Wettbewerbsverbot nichtig ist, wenn die Vereinbarung keinen Anspruch des Arbeitnehmers auf eine Karenzentschädigung beinhaltet, was einen Verstoß gegen Paragraf 74 Abs. 2 Handelsgesetzbuch (HGB) darstelle. Weder Arbeitgeber noch Arbeitnehmer könnten aus einer solchen Vereinbarung Rechte herleiten. Eine in Allgemeinen Geschäftsbedingungen enthaltene salvatorische Klausel führe nicht - auch nicht einseitig zugunsten des Arbeitnehmers zur Wirksamkeit des Wettbewerbsverbots.

Wegen der Notwendigkeit, spätestens unmittelbar nach der Beendigung des Arbeitsverhältnisses eine Entscheidung über die Einhaltung des Wettbewerbsverbots zu treffen, müsse sich die (Un-)Wirksamkeit aus der Vereinbarung ergeben. Daran fehle es bei einer salvatorischen Klausel, nach der wertend zu entscheiden sei, ob die Vertragsparteien in Kenntnis der Nichtigkeit der Vereinbarung eine wirksame Vereinbarung abgeschlossen hätten und welchen Inhalt die Entschädigungszusage gehabt hätte.

\section{VERSTOSS GEGEN $\S 74$ ABS. 2}

